lishment (U.K.) and Mr. Arthur A. Regier, National Aeronautics and Space Administration (U.S.A.). Prof. Lighthill, and also Prof. P. L. Bhatnagar, of the Indian Institute of Science, presided over the sessions on fluid mechanics, and interesting papers were presented on flow in bent pipes, transition, the nature of turbulence, boundary layer problems in hypersonic flows and models for plasma oscillations. Dr. Frank L. Wattendorf, director, Advisory Group for Aeronautical Research and Development (NATO), presided over the session on wind-tunnel design and testing, aircraft propulsion and flight research. Papers were presented on wind-tunnel design problems, particularly at high subsonic and transonic speeds. Particular interest was shown in a report by $\mathrm{Mr}$. F. W. Hooton, of the Aeronautical Research Laboratories, Australia, on the formation of a flight research group in his laboratories. Prof. S. V. C. Aiya, of the Indian Institute of Science, presided over the session on aviation electronics, and interesting papers were presented, of which Mr. W. A. Johnson's paper on recent researches done at the Royal Aircraft Establishment in the field of aviation electronics, and that of Mr. L. R. Lucassen, National Aero- and Astronautical Research Institute, Holland, on an instationary method for measuring antennæ radiation patterns of the Fokker-27 in flight, evoked considerable interest.

On the last night, a banquet was arranged at the Century Club, Bangalore. Dr. P. Nilakantan proposed a toast to "The Delegates", and Prof. Lighthill, replying to the toast, proposed a toast to "The National Aeronautical Laboratory". Several of the foreign delegates spoke expressing their personal sentiments, congratulating the National Aeronautical Laboratory on holding the seminar. The final session terminated with a vote of thanks by Dr. Y. V. G. Acharya to all delegates and the staff of the National Aeronautical Laboratory for their valuable cooperation in making the seminar a success.

\title{
UNITY IN THE ELECTRICAL INDUSTRY
}

$\mathrm{T}$ HE title chosen by Mr. G. S. C. Lucas for his presidential address, delivered before the Institution of Electrical Engineers on October 5, was "Unity in the Electrical Industry".

After a brief reference to the forty-five years which he had himself spent in the industry, Mr. Lucas proceeded to review from several different points of view the changing pattern of the industry over the past half-century, to demonstrate a certain unity and continuity in its development, and to derive from these some inferences as to the pattern for the future.

Its man-power being the industry's most important asset, Mr. Lucas began his review by a survey of the growth and deployment of the scientific and technical personnel of the electrical industry over the period 1925-60. From the membership records of the Institution of Electrical Engineers it was possible to estimate fairly accurately the number of professionally qualified electrical engineers active in the United Kingdom at any given time. A similar estimate could be made of those qualified by education and training but who at the time had not achieved full professional status.

Data from which the numbers of technicians can be estimated are less readily available. The educational qualifications of technicians are normally derived from National and Higher National Certificate courses or from City and Guilds courses, but a substantial fraction of Higher National Certificate holders have qualified for corporate membership of the Institution of Electrical Engineers and thus fall in the professional group. In computing the numbers of technicians it has been assumed that 45 per cent of all who sat for the Higher National Certificate finally qualified for Graduate membership of the Institution. An appropriate correction has been applied for deaths and retirements, and it is further assumed that 20 per cent have gone abroad. The progressive totals derived from these computations together with the figures for professional electrical engineers are given in Table 1 .

Mr. Lucas directed particular attention to the rapid rise in the number of technicians, a factor not always taken into account in assessing our man-power resources. In a paper entitled "Recruitment of Pro-

\begin{tabular}{|c|c|c|c|c|c|}
\hline \multicolumn{6}{|c|}{ Table 1} \\
\hline \multirow{4}{*}{$\begin{array}{l}\text { Professional man-power } \\
\text { Technician man-power: } \\
\text { National Certificate } \\
\text { City and Guilds }\end{array}$} & 1930 & 1940 & 1950 & 1955 & 1960 \\
\hline & 8,300 & 14,250 & 24,000 & 30,000 & 38,000 \\
\hline & $\begin{array}{l}\mathbf{1}, 960 \\
\mathbf{2}, 360\end{array}$ & $\begin{array}{l}8,960 \\
9,150\end{array}$ & $\begin{array}{l}22,600 \\
20,000\end{array}$ & $\begin{array}{l}36,500 \\
23,200\end{array}$ & $\begin{array}{l}69775 \\
25,000\end{array}$ \\
\hline & 4,320 & 18,110 & 42,600 & 59,700 & 94,775 \\
\hline
\end{tabular}

fessional Electrical Engineers", read before the Institution in $1958 \mathrm{he}$ had emphasized the increasing importance of the technician to the electrical industry, pointing out that technicians hold posts of responsibility at all levels between that of the craftsman and that of the professional electrical engineer. He had expressed the opinion that new fields of activity for technicians were opening up with the development of design methods based on computers and analysers and of new methods of presentation of design information applicable to the electronic control of machine tools. The time had come when technician qualifications should be recognized as something honourable and worth while in their own right. It was to be hoped, he said, that before long the existing confusion resulting from the use of the National Certificate route as a channel for professional as well as for technician qualifications would come to an end.

Proceeding to a comparison of British electrical engineering man-power with Russian and American, Mr. Lucas gave a table of totals and of numbers per ten thousand of population for the United Kingdom from 1930 together with the corresponding data for the U.S.S.R. and the United States, in so far as these were available. From this analysis Mr. Lucas concluded that, in proportion to our population, we have in Great Britain a good body of well-educated electrical engineers and electrical technicians. He went on to say, however, that the differences in total man-power do not alone explain the failure of Great Britain, in many instances, to exploit quickly and effectively scientific discoveries and inventions which have originated here. The trouble, he believed, lay not so much in the smaller total forces of technical personnel which we could deploy as in their dispersal. Our technical resources were being dissipated in repetition of the development of the same apparatus and devices by separate research, development and 
design teams in different establishments. The possibilities of such duplication were evidenced by the numbers of separate companies designing and manufacturing particular lines of electrical equipment. The point was illustrated by data from the return of trade associations for 1959. In that year in Great Britain the numbers of separate companies engaged in certain classes of electrical and allied manufactures were as follows:

Power transformers
Steam turbines
Domestic appliances
Switchgear
Control gear
Small switch and fuse gear
Domestic radio and television sets
Semi-conductor devices

Fortunately there had been in recent years a trend towards the creation of larger industrial units and this was a trend which must be encouraged if we were to use our technical man-power efficiently.

Turning from the human to the technological side of electrical engineering, Mr. Lucas directed attention to the fact that a major division had developed forming two branches known, respectively, as those of 'electronics' and 'power'.

Starting with the Fleming diode of 1904, the electronics industry now comprised radio and television and radar, electronic automatic control, computing and electronic switching. Side by side in the power field there had been developments, not perhaps so spectacular, but none the less, very great. Substantial advances had resulted from improvements in materials. In power generation, steam turbine generating unit ratings had increased five hundred fold from the early years of the century. At that time a unit rated at 1 megavolt-ampere (MVA) would have a steam temperature of $580^{\circ} \mathrm{F}$. at a pressure of $200 \mathrm{lb} / \mathrm{sq}$. in. To-day units of $550 \mathrm{MVA}$ rating were being designed and built to utilize steam at $1,050^{\circ} \mathrm{F}$. and a pressure of $2,350 \mathrm{lb} . / \mathrm{sq}$. in. Power transformers had increased from 15 MVA at $33 \mathrm{kV}$. to 570 MVA at $400 \mathrm{kV}$., the upper limit of size now being determined by transport limitations. Rectification from alternating to direct current for such purposes as industrial electrolysis, electric traction or for heavy industrial drives had been developed, utilizing mercury are rectifiers or semi-conductor rectifiers. It was, however, probable that the development of the controlled semi-conductor rectifier might lead to the elimination of the mercury are rectifier. In the specialized field of electric power supply for aircraft, generating equipment for a modern airliner represented a capacity of $300 \mathrm{kVA}$. Nuclear power stations were in operation, designs well established, and the output ratings of successive stations increasing in steady progression. There were, however, under consideration the possibilities of electricity generation by direct methods of energy conversion by fuel cells, thermoelectric devices, magneto-hydrodynamics or from nuclear fusion.

Although it had been argued that these two branches of the electrical industry were separate and distinct with little in common, it was becoming daily more clear that not only did their interests largely overlap but they were becoming interdependent in a very marked degree. Electronic devices for sensing, measuring and controlling, often in association with elaborate computing equipment, had become essential elements in the applications of electric power. These assemblies of electronic circuits and the power units which they controlled had, in fact, become the 'building bricks' of industrial development.

These considerations brought into sharp relief the characteristics of a type of engineer whose activities, although not unfamiliar to the industry in the past, were taking on a greatly inereased significance. This was the application engineer. Such an engineer would require to have a knowledge of the new developments both in power and electronies, a full understanding of the principles of automatic control, and facility in the use of the tools of his trade, the digital and analogue computers by means of which his stability equations would be solved. The application engineer would not, of course, have the detailed knowledge of machines or electronic devices required by the designer but rather a good broad working knowledge. $\mathrm{He}$ must, in addition, have specialist knowledge of some branch of the particular industry which he serves, as, for example, the steel industry, mining, chemical and oil, paper and printing, aircraft and marine.

The increasing interrelation of the two main branches of the industry was associated with and indeed in large measure originated from modern developments in nuclear and in solid-state physics. There were in these facts important implications relating to the education and training of electrical engineers. They appeared to call for common basic curricula in our colleges and universities for 'power' and 'electronics' engineers. In addition, schemes of practical training in industry should be subject to re-examination.

J. Greig

\section{THE NATURE CONSERVANCY}

$\mathrm{T}$ HE report of the Nature Conservancy for the year ended September 30,1961 , is commendable both for the speed with which it has been produced and for the encouraging progress it records*.

During the year there has been significant progress towards making conservation effective as a balanced and co-ordinated whole; there has also been an increasing sum of research results and a growing impact of research on management and land use.

Scientific management of the Island of Rhum, for example, is now yielding a substantial amount of meat (in's he form of venison) for human consumption.

- Report of the Nature Conservancy for the year ended 30th September, 1961. Pp. vil + 114 + 14 plates. (London: H.M.S.O., 1961.) 8. bd. net.
At the same time, the vegetation of the Island which was previously deteriorating rapidly is now recovering and improving in composition; a considerable acreage has been released for afforestation, and a successful research programme on deer population has been reconciled with precise control of numbers. The Conservancy has been able to contribute scientific information about red deer (Cervus elaphus) to assist the Red Deer Commission in starting successful dealings with the Highland deer problem as a whole. A scientific basis has also been found for a new approach to the management of grouse moors.

Encouraging progress has been made with the working out of methods of managing water catch- 